\title{
O DICIONÁRIO E O IMAGINÁRIO DO VERBETE GOLPE
}

EL DICCIONARIO Y EL IMAGINARIO DE LA ENTRADA GOLPE

\author{
THE DICTIONARY AND THE IMAGINARY BEHIND THE TERM GOLPE
}

\author{
Maria Sirleidy de Lima Cordeiro* \\ Universidade Federal de Pernambuco
}

RESUMO: Este estudo pretende apresentar uma discussão teórica e analítica sobre os processos de significação do verbete golpe dentro de um recorte da história lexicográfica, a fim de compreender os sentidos (des)estabilizados nos dicionários dos séculos XVIII, XIX e XX. Para fundamentá-lo, adotamos o dispositivo teórico-analítico da História das Ideias Linguísticas e da Análise do Discurso de linha francesa. A articulação dessas perspectivas apresenta-se de modo interessante e significativo para discutir os sentidos do verbete golpe, uma vez que uma palavra tem memória e história cujos sentidos evocam um saber e um imaginário sobre a língua. Com este estudo, concluímos que, ao fazer parte da língua imaginária, o dicionário, na história das práticas lexicais, desestabiliza os sentidos e ainda marca confrontos e alianças que, por vezes, são esquecidos ou retomados e transformados em discursos que afetam a historicidade desse verbete numa temporalidade própria para a lexicografia.

PALAVRAS-CHAVE: Lexicografia. História das Ideias Linguísticas. Golpe.

RESUMEN: Este estudio presenta una discusión de los procesos de significación de la entrada golpe dentro de un recorte de la historia lexicográfica, con el fin de comprender los significados estabilizados, o desestabilizados, en los diccionarios de los siglos XVIII, XIX y XX. Para apoyar este estudio, hemos adoptado el dispositivo teórico y analítico de la historia de las ideas lingüísticas y el Análisis del Discurso de orientación francesa. La articulación de estas perspectivas se presenta significativa para discutir la definición de la entrada golpe, una vez que entendemos que una palabra tiene memoria e historia cuyos sentidos evocan un conocimiento y un imaginario sobre la lengua. Concluye que el diccionario, al estabilizar los sentidos de la entrada golpe, no deja la lengua estable e ilesa; por el contrario, observamos una lengua imaginaria atravesada por movimientos de resistencia y contradicciones que evocan otros discursos que se encuentran en su materialidad.

PALABRAS-CLAVE: Lexicografía. Historia de las Ideas Lingüísticas. Golpe

* Doutoranda em Letras, na área de Linguística, pelo PPGL da UfPE, participa do grupo de estudos NELFE. Realizou DoutoradoSanduíche em Portugal pela Universidade Católica Portuguesa (UCP). E-mail: sirleidy_lima@hotmail.com. 
ABSTRACT: This study intends to present a theoretical and analytical discussion about the processes of signification involving the word golpe (coup) in a lexicographic history perspective in order to understand the (de)stabilized senses in the XVIII, XIX and XX century dictionaries. For this study, we articulated perspectives from the fields of History of Linguistic Ideas and French Discourse Analysis, in order to discuss the senses of the word golpe, understanding that a word has a memory and a history whose meanings evoke a knowledge and an imaginary about a language. With this study, we conclude by becoming part of the imaginary language, the dictionary, in the history of lexical practices, destabilizes the senses and marks confrontations and alliances that are forgotten or sometimes recovered and transmuted into discourses that affect the lexicographic historicity and temporality of this word: coup. KEYWORDS: Lexicography. History of Linguistic Ideas. Coup.

\section{INTRODUÇÃO}

Discorrer acerca do imaginário do verbete golpe é compreender que "[...] quando uma palavra significa é porque ela tem uma textualidade, ou seja, porque a sua interpretação deriva de um discurso que a sustenta, que a prevê de realidade significativa" (ORLANDI, 2004, p. 52). É sob essa perspectiva que este estudo pretende apresentar uma discussão teórica e analítica sobre os processos de significação do verbete golpe em alguns dicionários do século XVIII, XIX e XX.

O estudo é fundamentado no arcabouço teórico-analítico da História das Ideias Linguísticas (HIL) no Brasil e articulada com a Análise de Discurso (AD). Nessa articulação teórica encontram-se estudos desenvolvidos por Orlandi (1990, 2002, 2004), Pêcheux (1988), Silva (1996) e por Nunes (1992, 1996, 2002, 2006, 2008b) para compreender, dentro de um recorte da história lexicográfica, a importância dos instrumentos linguísticos na sua relação imaginária com o saber linguístico, com a sociedade e a história, sem descartar o político e o ideológico.

Assim, partimos do pressuposto de que o dicionário se configura como um objeto discursivo (NUNES, 1996). Nessa perspectiva, o dicionário apresenta processos de significação que produzem efeitos na produção do saber linguístico, bem como é atravessado por saberes sobre a língua, os quais marcam momentos importantes que evocam a história e a memória, desestabilizando e estabilizando sentidos.

Investigar o verbete golpe nos dicionários é interessante porque o Brasil atravessou/atravessa momentos de instabilidade política que marcam a história e a memória do país; dentre eles, podemos destacar o golpe ${ }^{1}$ de 1964 . Esse acontecimento ocorrido no século XX originou o interesse de analisar os processos de significação do verbete golpe nos séculos XVIII ao XX pelo dispositivo teóricometodológico da AD e da HIL, para observar os deslizamentos, os acréscimos/apagamentos de sentidos deste verbete nos dicionários, como também ressaltar a relevância que a linguagem possui na relação com a sociedade e a história.

Então, em face dessas proposições, pretendemos investigar o processo de significação do verbete golpe nos dicionários, traçando um percurso histórico e discursivo, uma vez que "[...] os dicionários, como lugares de escuta e de escrita da sociedade, constituem memórias da língua nacional, organizadas por meio de diferentes filiações sócio históricas” (NUNES, 2008b, p. 371).

\section{ALGUMAS CONSIDERAÇÕES SOBRE A ARTICULAÇÃO ENTRE A HISTÓRIA DAS IDEIAS LINGUÍSTICAS NO BRASIL E A ANÁLISE DO DISCURSO}

A Análise do Discurso de linha francesa (AD) constitui-se como um campo epistemológico consistente para os estudos linguísticos e ocupa um lugar muito importante para os estudos da História das Ideias Linguísticas (HIL) no Brasil, uma vez que, conforme

\footnotetext{
${ }^{1} \mathrm{O}$ Golpe de 64 foi um movimento orquestrado pelas forças militares que culminou com a derrubada do presidente João Goulart, eleito democraticamente pelo povo através do voto direto, quando este se encontra em viagem à China Comunista, fundamentado e justificado no combate à expansão comunista no país. Essa trama acarretou em um novo parêntese na frágil democracia brasileira, culminando em vinte e quatro longos anos de uma ditadura militar, um dos capítulos mais tristes e sombrios da história política e social do Brasil, conforme salienta Toledo (2014).
} 
Nunes (2008a), essa articulação aponta para a necessidade de se pensar sobre o modo como são realizadas as leituras dos dicionários e de considerar a "história das leituras" e a "história do sujeito-leitor", conforme salienta Orlandi (1988) no livro Discurso e Leitura. Nessa perspectiva, a AD como um modo de leitura, sustentado por um dispositivo teórico e analítico que considera a historicidade dos sujeitos e dos sentidos, traz contribuições para os estudos da HIL (NUNES, 2008a).

Desse modo, é na articulação entre a História das Ideias Linguísticas e a Análise do Discurso que este estudo pretende discutir a definição do verbete golpe, pois compreendemos que uma palavra tem memória e história cujos sentidos estabilizados no dicionário não obedecem ao acaso; pelo contrário, marcam as condições de produção e representam imaginariamente o saber sobre a língua. Conforme Nunes (2008a, p. 111),

[...] há então uma produtividade específica quando a AD se posiciona no entremeio com a HIL. Podemos dizer que esse modo de fazer história da ciência tem consequências para a leitura e mesmo para a produção de arquivos relativos às ciências da linguagem. Isso inclui tanto os trabalhos de análise dos textos de arquivo, dos gestos de leitura que deles se depreendem, quanto a proposição de novas formas de escrita do arquivo, sensíveis à historicidade dos sentidos, à pluralidade dos domínios das ciências da linguagem, à espacialidade e à temporalidade do conhecimento, às formas de autoria, aos funcionamentos institucionais, aos acontecimentos, enfim, a tudo aquilo que compreende as condições de produção dos discursos.

Nessa perspectiva, a articulação entre a HIL e a AD mostra-se relevante visto que os estudos sobre os instrumentos linguísticos se distanciam da concepção de uma ciência positivista cujos objetos de investigação - como, por exemplo, os dicionários -, são analisados sob uma ótica homogênea e acabada; e passam a ser considerados como objetos discursivos atravessados pela relação com a sociedade e a história. Além disso, por entendermos que o dicionário é materialidade discursiva e ideológica - perspectiva teórica postulada pela $\mathrm{AD}^{2}$ - não ignoramos o político, isto é, a resistência, os movimentos e as relações de força no processo de significação e estabilização de um verbete no dicionário.

Seguindo essa articulação, é possível compreender e ler o dicionário como discurso, analisando o funcionamento discursivo de um verbete - a organização dos enunciados fragmentados do dicionário em um discurso histórico, as formas discursivas - e observando os processos de significação - as repetições, os deslizamentos de sentidos, as definições (NUNES, 1996). Assim, dicionarizar um verbete é uma ação com confrontos e movimentos que afetam o político, o ideológico e a historicidade dos sentidos do verbete dicionarizado e, consequentemente, a língua.

Para Nunes (1996), o dicionário é um espaço de memória atravessado por alianças ou confrontos na história das práticas lexicais que no decorrer do tempo é esquecido, transformado e atualizado. Ao imbricar os relatos dos dicionários com a memória, faz-se necessária a relação entre o interdiscurso (o já-dito) com o intradiscurso (o que se está dizendo) (ORLANDI, 2001), pois essa relação salienta " [...] o conjunto dos fenômenos de 'co-referência' que garantem aquilo que se pode chamar o 'fio do discurso', enquanto discurso de um sujeito" (PÊCHEUX, 1988, p. 166). Assim, compreendemos que o dicionário se configura como muito mais do que uma obra com regras estáticas de definições e sentidos da língua, e constitui-se como um objeto discursivo.

Por conseguinte, o dicionário causa efeitos na produção de saber linguístico, bem como é atravessado por saberes sobre a língua, os quais marcam momentos importantes da história, desestabilizando e estabilizando sentidos.

\section{PERCURSO METODOLÓGICO E ANALÍTICO DO ESTUDO}

A metodologia utilizada é baseada na abordagem qualitativa. Como já afirmamos, está fundamentada sob o arcabouço teóricometodológico da História das Ideias Linguísticas no Brasil e articulada com a Análise de Discurso.

${ }^{2}$ Trataremos adiante o modo como a HIL compreende e trabalha o dicionário. 
Nessa articulação teórica, encontram-se estudos desenvolvidos por Eni Orlandi (1990, 2002, 2004) - para compreender a emergência de um saber metalinguístico, por exemplo - e por José Horta Nunes (2002, 2006, 2008b) - para compreender a importância dos instrumentos linguísticos, como gramáticas e dicionários, na sua relação constitutiva com a sociedade e a história. Vale salientar que neste trabalho estamos analisando os dicionários.

A constituição do recorte discursivo para análise é um aspecto muito importante, uma vez que não se dá de modo estanque, linear nem completo; dá-se a partir de alternâncias de momentos entre a superfície linguística e os processos discursivos, isto é, em movimentos analíticos contínuos a partir dos questionamentos e inquietações que são feitos sobre os fatos discursivos (NUNES, 1992). Desse modo, o procedimento de análise buscou encontrar os processos de significação do verbete golpe dentro de um recorte da história lexicográfica do Brasil.

O trabalho está organizado a partir da coleta de sete dicionários dos séculos XVIII, XIX e XX. A seleção dos dicionários, descritos abaixo, justifica-se como procedimento teórico-metodológico relevante para a realização desse estudo, uma vez que tais dicionários marcam momentos significativos para a elaboração de uma história da lexicografia brasileira, a partir de uma perspectiva discursiva (NUNES, 1996). Vejamos:

(1) o dicionário de Raphael Bluteau, o Vocabulario Portuguez e Latino, de 1712-1728, é um dicionário bilíngue (Português-Latim), no entanto, é o primeiro dicionário de Língua Portuguesa que apresenta as definições em português (NUNES, 1996).

(2) o Dicionário da Lingua Portuguesa, datado em 1789, foi elaborado por Antonio de Moraes Silva, a partir do Dicionário Latino-lusitano de Bluteau. Tal dicionário introduz discursivamente a tradição europeia no Brasil, apresentando as definições em português, e inaugura um novo viés para a lexicografia brasileira (NUNES, 1996). Conforme Nunes (1996), Moraes Silva obteve muitas edições de dicionários por todo o século XIX e também algumas edições no século XX. Para este estudo, além do primeiro dicionário de 1789, vamos observar um do século XIX, o dicionário intitulado de Dicionário da Língua Portuguesa, de 1813, e o do século XX, o dicionário intitulado de Grande Dicionário da Língua Portuguesa, de 1945. Vale salientar que esse último dicionário é de autoria de Moraes Silva, mas tem a colaboração de Augusto Moreno, Cardoso Junior e José Pedro Machado;

(3) o dicionário Grande e Novíssimo Dicionário da Língua Portuguesa de Laudelino Freire, do século XX - de 1939-1944 - conforme Nunes (2008, p. 360), "[...] é um dos um dos primeiros dicionários gerais brasileiros. Nele a distância entre uma elite letrada, os "homens de letras", e as camadas populares, é fortemente explicitada";

(4) o dicionário de Adalberto Prado e Silva, Novo Dicionário Brasileiro Melhoramentos Ilustrado, de 1962, e o dicionário de Aurélio Buarque de Holanda Ferreira, Novo Dicionário da Língua Portuguesa, de 1975, são dois dos mais representativos dicionários gerais brasileiros desse último momento (NUNES, 2008).

É sob esse recorte que este trabalho discute o funcionamento discursivo do verbete golpe, considerando os aspectos linguísticos e históricos, bem como apresenta os processos de significação desse verbete em alguns dicionários dos séculos XVIII, XIX e XX.

\section{DICIONÁRIOS COMO OBJETOS DISCURSIVOS}

Ao falar do imaginário do verbete golpe nos dicionários no século XVIII XIX e XX, levamos em conta a passagem da lexicografia portuguesa à lexicografia brasileira. De acordo com Nunes (1996, p. 20), "[...] a lexicografia brasileira aparece com o movimento de expansão das nações europeias, a partir da exploração e colonização do Novo Mundo”. Desse modo, o saber linguístico brasileiro apresenta uma forte filiação ao saber linguístico europeu, explicitando entrecruzamentos, repetições, continuidades e deslizamentos de sentidos. Essa produção de saberes relaciona-se com o processo que Auroux (2009) chama de gramatização das línguas.

Conforme Auroux (2009, p. 65), "Por gramatização deve-se entender o processo que conduz a descrever e instrumentar uma língua na base de duas tecnologias que são ainda hoje os pilares do nosso saber metalinguístico: a gramática e o dicionário”. Nessa 
perspectiva, o dicionário configura-se como uma tecnologia de gramatização da língua no qual são criadas condições instrumentais para a língua. Isso significa dizer que a língua não é um instrumento, a língua ganha um instrumento que oferece o pensar sobre a língua, para observar as definições estabilizadas e compreendê-las levando-se em conta o modo como as definições produzem sentidos em certas conjunturas, relacionadas à história e às condições de produção.

Nunes (2008b, p. 356) afirma que "[...] para o estudo das condições de produção dos dicionários tem sido muito produtivo o conceito de hiperlíngua, de Sylvain Auroux". Auroux (1997, p. 19) assevera que,

[...] a hiperlíngua designa um espaço/tempo estruturado pelos seguintes elementos: (i) diferentes indivíduos têm entre si relações de comunicação; (ii) tais relações se efetuam sobre a base de competências linguísticas, isto é, de aptidões atestadas por sua realização; (iii) as competências linguísticas individuais não são as mesmas; (iv) os indivíduos podem ter acesso (direto ou indireto) a instrumentos linguísticos, com os quais têm uma relação imaginária; (v) esses indivíduos mantêm atividades sociais; (vi) as relações de comunicação têm lugar em ambientes determinados.

Sobre o conceito de hiperlíngua, Nunes (2008b, p. 356) acrescenta que “[...] diz respeito não à língua de forma abstrata, mas sim, ao espaço-tempo onde se encontram os sujeitos falantes e onde se inserem também os instrumentos lingüísticos, que transformam as relações que esses falantes entretêm com a língua”. Desse modo, a hiperlíngua relaciona os dicionários à ideia de língua imaginária, o que permite, em um período de tempo, uma certa estabilidade nos sentidos dos verbetes dos dicionários.

A noção de língua imaginária surge em contraponto à ideia de língua fluída. Orlandi (1990, p. 75) postula que "[...] língua fluída língua-movimento, mudança contínua - pode ser observada quando se focaliza a história dos processos discursivos que constituem as formas de sentido da linguagem no seu contexto"; já a língua imaginária é aquela que os analistas fixam com suas sistematizações, fundados nos estudos linguísticos gramaticais e não-contextualizados. Nessa perspectiva, outra noção muito importante para esta discussão e para os dicionários como objetos discursivos é a noção de imaginário. Orlandi (1994) salienta a importância e a especificidade do imaginário na $\mathrm{AD}$, a autora afirma que

[...] não existe relação direta entre a linguagem e o mundo. A relação não é direta mas funciona como se fosse, por causa do imaginário. Ou, como diz Sercovich (1977), a dimensão imaginária de um discurso é sua capacidade para a remissão de forma direta à realidade. Daí seu efeito de evidência, sua ilusão referencial. Por outro lado, a transformação do signo em imagem resulta justamente da perda do seu significado, do seu apagamento enquanto unidade cultural ou histórica, o que produz sua "transparência". Dito de outra forma, se se tira a história, a palavra vira imagem pura. Essa relação com a história mostra a eficácia do imaginário, capaz de determinar transformações nas relações sociais e de constituir práticas (ORLANDI, 1994, p.57).

Assim, o dicionário encontra-se mais próximo da noção de língua imaginária e da relação da linguagem com a história uma vez que é fixada na história e apresenta nomenclaturas e definições produzidas por e para sujeitos em certas circunstâncias (ORLANDI, 1994; NUNES, 2008b). Vale salientar que embora o aparecimento dos dicionários contribua para a ideia de homogeneidade das línguas nacionais, ele não deixa ilesas as práticas linguísticas humanas, nem procura compreendê-las em sua transparência, mas na relação com os discursos que as constituem (NUNES, 2008b, 2008a; AUROUX, 2009). O modo como o dicionário estabiliza os sentidos afeta as práticas discursivas e produz efeitos tanto sobre a produção do conhecimento como sobre a maneira de compreender o mundo. Portanto, os dicionários apresentam um acontecimento discursivo situado na história que exibe alguns sentidos e que, no entanto, silencia vários outros.

Com respeito à leitura discursiva do dicionário, Auroux (2009) afirma que os dicionários são instrumentos linguísticos que materializam o saber metalinguístico, uma vez são vistos como um objeto discursivo que historiciza um dizer que remete aos conceitos discursivos - articulados pela HIL e AD - e introduz marcas ideológicas e de tensões políticas linguísticas.

Portanto, os movimentos de atribuir uma significação, de deslizamentos e acréscimos/apagamentos de sentidos marcam os processos de significação de um verbete, ajudam a “[...] ver o dicionário como parte da relação com a sociedade e a história” (NUNES, 
2008b, p.110). Como assevera Orlandi (2001, p. 8), “[...] transforma esses instrumentos em objetos vivos, partes de um processo em que os sujeitos se constituem em suas relações e tomam parte na construção histórica das formações sociais com suas instituições, e sua ordem cotidiana”.

Do ponto de vista da constituição do dicionário há marcações léxico-sintáticas que permitem relacionar o dicionário com o discurso da gramática, salienta Nunes (1996). Vejamos, no Quadro 1, essa marcação no verbete golpe:

Quadro 1: Marcações léxico-sintáticas

\begin{tabular}{c|c|c|c|c}
\multirow{4}{*}{$\begin{array}{c}\text { Século } \\
\text { XVIII }\end{array}$} & \multicolumn{2}{|c|}{$\begin{array}{c}\text { Vocabulario portuguez e latino } \\
\text { Raphael Bluteau } \\
(1712-1728)\end{array}$} & \multicolumn{2}{c}{$\begin{array}{c}\text { Dicionário da Língua Portuguesa } \\
\text { Antonio de Moraes Silva } \\
\text { (1789) }\end{array}$} \\
\cline { 2 - 5 } Século \\
XIX
\end{tabular}

Fonte: Produzido pela autora

Pelo que podemos evidenciar, no século XVIII - no dicionário de Raphael Bluteau (1712-1728) - não aparece nenhuma marcação léxico-sintática; já no dicionário de Moraes Silva (1789) - que, por sua vez, é o primeiro monolíngue e se baseia no dicionário de Bluteau - aparece a indicação da categoria gramatical e de gênero (s.m. substantivo masculino), enfatizando que o verbete golpe é um substantivo masculino. No século XIX, o dicionário de Moraes Silva (1813) permanece com a mesma marcação da categoria gramatical e de gênero (s.m.) do verbete golpe.

No século XX, além da indicação da categoria gramatical (s.m), há outros acréscimos, como as marcações sobre a etimologia do verbete golpe. O Grande e Novíssimo Dicionário da Língua Portuguesa, de Laudelino Freire (1939 -1944), apresenta a indicação léxico-sintática (s.m.), situa o verbete no Brasil, com a letra $\boldsymbol{B}$, e enfatiza a origem do verbete em latim, com lat. colpus.

No Dicionário da Língua Portuguesa, de Antônio de Moraes Silva (1945), há as mesmas marcações do dicionário de Laudelino Freire (1939 - 1944), com a diferença que a marcação etimológica do latim é colpu-. No Novo Dicionário Brasileiro Melhoramentos Ilustrado, de Adalberto Prado e Silva (1962), o verbete golpe é apresentado com a categoria gramatical s.m., a marcação da origem grega gr. Kolaphos, pelo l. v.. No Novo Dicionário da Língua Portuguesa, de Aurélio Buarque de Holanda Ferreira (1975), há a indicação da origem grega e o sentido em português gr. Kólaphos, 'bofetada', e a origem do latim³ colophu, além da categoria gramatical (s.m.).

${ }^{3}$ Vale ressaltar que a escrita do verbete golpe na origem do latim apresenta as duas grafias: Colophu e colpus, sendo colpus filiada ao latim vulgar. 
Desse modo, vemos que há repetições, exceto no dicionário de Bluteau, quanto à mesma filiação de categoria gramatical, substantivo masculino (s.m.), bem como é introduzida a origem etimológica, do latim e do grego, no verbete golpe nos dicionários do século XX. Assim, a relação do dicionário com o discurso da gramática é evidenciada, pois as indicações léxico-sintáticas enfatizam essa relação, instauram "[...] um modo de enunciar que se está no interior de um dicionário de língua e tudo o que vem nos verbetes se relaciona com a significação na língua portuguesa”, conforme salienta Nunes (1996, p. 193).

Por conseguinte, ainda é preciso dizer que a marcação da categoria gramatical, nos dicionários analisados, funciona como uma espécie de instrumento para ensinar e indicar os padrões normativos da língua, produzindo um efeito imaginário de conhecimento linguístico sobre a língua, atravessado por discursos que evocam a historicidade e os aspectos constitutivos dos sentidos.

\section{ANALISANDO OS PROCESSOS DE SIGNIFICAÇÃO DO VERBETE GOLPE}

Como já afirmamos, nossas análises do verbete golpe afastam-se da perspectiva positivista e conteudista, em que o dicionário é visto sob uma ótica de complementaridade na instrumentação e descrição da língua. Destoando dessa perspectiva normativa, assumimos o dicionário como um objeto discursivo marcado pelo político, pelo ideológico e, também, atravessado por vários discursos que evocam uma história e memória (NUNES, 1996, 2008a; ORLANDI, 2001).

No dicionário, encontramos os sentidos estabilizados que remetem às condições de produção e à memória, isto é, a significação de um verbete sinaliza uma dimensão histórica (SILVA, 1996). Assim, o dicionário é capaz de apresentar enunciados definidores que estabilizam e evocam o imaginário do verbete golpe. Vejamos algumas definições ${ }^{4}$ na Figura 1:

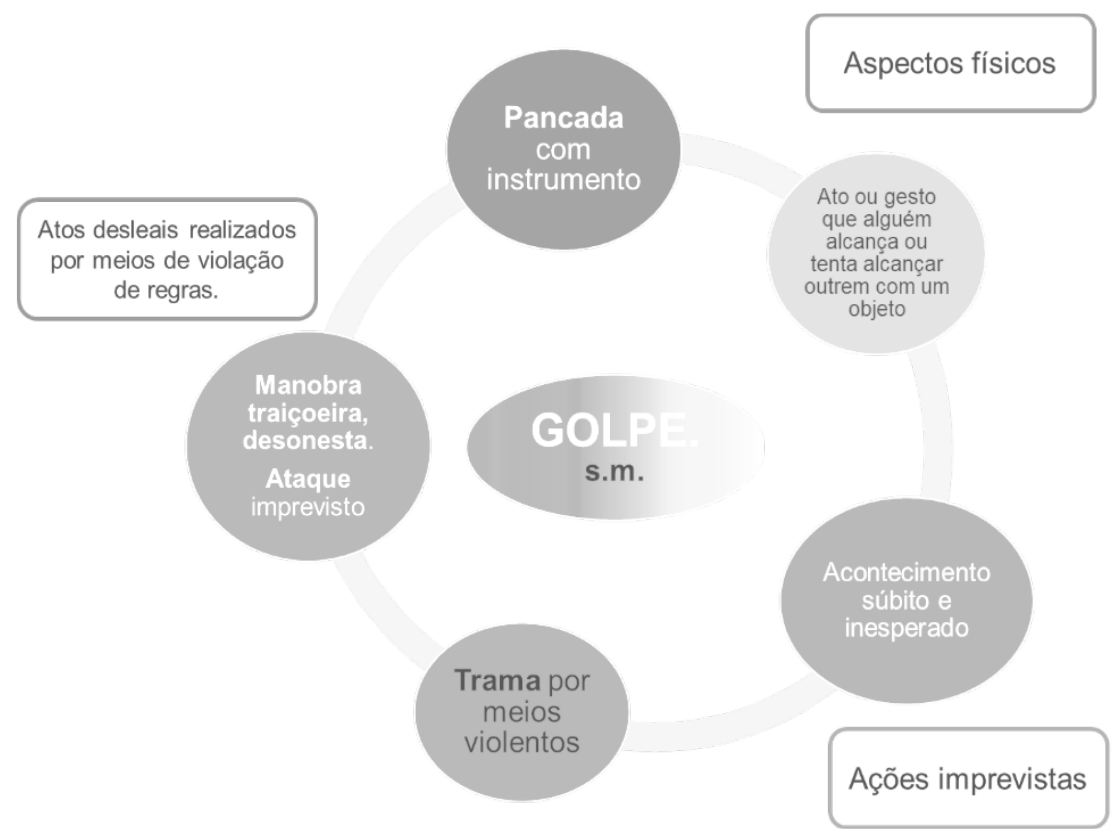

Figura 1: Imaginário do verbete Golpe nos dicionários XVIII, XIX e XX.

Fonte: Elaboração nossa a partir dos dicionários analisados

\footnotetext{
${ }^{4}$ Vale salientar, porém, que essas definições foram as que mais se destacaram diante diversos enunciados, visto que fomos estabelecendo interpretações, (re)agrupando enunciados e construindo relações parafrásticas no decorrer do recorte discursivo do verbete golpe nos dicionários. Desse modo, o verbete golpe foi estabilizando esses sentidos, apresentados na figura, que permeiam as produções lexicográficas do século XVIII, XIX e XX e remetem a sentidos que conseguimos relacionar com a história do saber linguístico.
} 
A partir da Figura 1, vemos que o dicionário, enquanto tecnologia de gramatização, indica a categoria gramatical (s.m.), definições que apresentam repetições, deslocamentos de sentido e traz uma caminhada histórica no processo de significação do verbete golpe. Por isso tal verbete está sempre em movimento e atravessado ideologicamente.

Notemos que no imaginário do verbete golpe os sentidos estabilizados, de modo geral, são:

$>$ Pancada com instrumento

$>$ Ato ou gesto que alguém alcança ou tenta alcançar outrem com um objeto

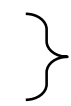

\section{Golpe relaciona-se com os aspectos} físicos/ao corpo

\section{Golpe relaciona-se a ações imprevistas}

\author{
Golpe relaciona-se a atos desleais \\ realizados por meios de violação de regras
}

O verbete golpe, no processo de significação, atravessa diversos tipos de discursos, que marcam e transformam os sentidos estabilizados de um conhecimento linguístico e, reciprocamente, marcam e transformam a memória e a história. Desse modo, fazse necessário convocar a afirmação de Nunes (1996, p. 29),

[...] o discurso lexicográfico, seja qual forem os domínios de uso das palavras, é "instituído" e "informado" pelo discurso social e histórico, o que conduz a dois pontos essenciais: o problema da circularidade e o da heterogeneidade das definições. Está em jogo aí a questão da recepção, do reconhecimento do discurso pelo leitor diante da polifonia discursiva e também o problema das incoerências das definições lexicográficas, marcado pela articulação dos discursos, pela invasão de um discurso por um outro. Enfim, pela historicidade constitutiva dos sentidos.

Nessa perspectiva, vamos observar, no Quadro 2, a definição do verbete golpe no século XVIII nos dicionários Vocabulario Portuguez e Latino, de Raphael Bluteau (1712-1728), e no Dicionário da Língua Portuguesa, de Antonio de Moraes Silva (1789). Nunes (1996) afirma que a relação entre esses dois dicionários é interessante pois os enunciados e a reformulações dos discursos salientam uma variação, a partir da rede de substituições, de paráfrases e de sinonímias.

Quadro 2: Verbete golpe século XVIII

\section{SÉCULO XVIII}

Vocabulario portuguez e latino de Raphael Bluteau (1712-
Dicionário da Língua Portuguesa de Antonio de Moraes Silva

(1789) 
GOLPE. Pancada. IEtus, us. Mafc.CIc. Plaga, \&. Fem. Virgil. Vid. Pancada. Algumas vezes se usa de percussus, us. Malsc. \& de Percussio, onis. Fem.

Desta opiniaõ nacem os differentes modos de se mostrar anojado, como são os golpes, que se dão nos peitos, nas pernas, na cabeça,.\&c. Ex bac opinione front illa varia genera lugendi, peEtoris, faminu, capitus percussiones. O que tem tido hum golpe na cabeça. IEtus caput. Cefar. Em lugar de secundu capu, ou capite. Golpe do tambor, quando se bate. Tympani pulfatio, onis. Fem. Tito Livio diz Pulfatio Fcutorum. A acção de dar golpes nos escudos. Os mysterios dolorosos nos Golpes do tympano. Vierira, Tom. 5.198. Deu três golpes à porta. Ostium ter pulsavit. Golpe. Copia. Quantidade. Hum bom golpe de dinheiro. Inges pecúnia, \&. Fem. Cic. Hum golpe de vinho. Parum vini, Façafe a massa com huma oitava de farinha \& hum Golpe de vinho. Arte da cozinha, pag. 24. Sahio de dentro do templo hum Golpe de agoa, tão copioso. Mon. Lusitan. Tom. 2. i. col. 2.

Hum grande Golpe de cavalaria. Guerra do Alemrejo. 17. Valida manus equitum. Ex Tacito, Cesare. Golpe. Infurtunio. Desgraça. Vid. Nos seus lugares. Senti este golpe. Hoc percussus sum. Id. Golpe. Ferida. Vid. No seu lugar. De golpe. Juntamente. Na mesma hora. No mesmo tempo. Todas estas mesmas cousas me vicraõ de golpe. Hac omnia simul, ou uns, ou pariter, ou eodem tempore mihi obtigerwit. Para me oprimir as desgraças me vem de hum golpe. Mihi ad malum mala res plurima fe agglutinant. Plaut. O adagio Portuguez diz, Quem deita agoa na garrafa de golpe, mais derrama do que colhe. De golpe. Subitamente. Repente. Subito. Os, que fobem de Golpe a grandes lugares. Marinho, Apologet. Discurlos, 140. Golpes no vestido. São huns cortes ao comprido com ordem,

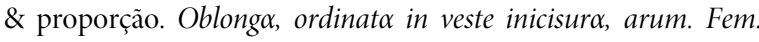
Plur.
GOLPE, s.m. pancada, ou ferida de corpo impelido, ou atirado. $\$$ Copia, quantidade v. g.,, hum bom golpe de pedraria, Amaral 7:,, hum bom golpe de dinheiro, de vinho, de água. M. Conq. $\$$-- de cavalaria, ou infantaria de gente. B. i. § Ajuntou hum golpe dos seus, Castan. 3. f. 218. \$f. Infortunio, desgraça v. g. por morte. \$ Talho, que se fazia por ornato nos vestidos antigos, tinhão por baixo vivos, ou estofos de còr diversa do d peça. $₫$ De golpe, adv. A hum tempo; de repente v. do Arceb. i. 5. De hum golpe, de huma vezv. g. ,, por de hum golpe gente no muro inimigo assalto,, Castan. L. 3. F. 214 § Golpe de mestre, rasgo, lance, acção de homem, que sabe bem daquilo a que se refere o golpe.

Em relação ao dicionário de Bluteau (1712-1728), a definição de golpe apresenta muitos termos e expressões linguísticas em latim, pois esse dicionário é bilíngue (Português-Latim. A definição também é mais extensa, se comparada à definição de Moraes Silva (1789). Notemos que, além da definição, há trechos para exemplificar o que foi explicitado, como por exemplo:

De golpe. Juntamente. Na mesma hora. No mesmo tempo. [...]

Para me oprimir as desgraças me vem de hum golpe.
Definição

Exemplo 
Desse modo, o dicionário de Bluteau apresenta possibilidades de sentidos e de situações de uso do verbete golpe.

No que se refere ao dicionário de Moraes Silva, a definição de golpe é mais compacta, visto que ele não exibe as expressões em latim nem exemplos de uso do verbete. Todavia, há algumas repetições de algumas definições, a saber: "\$ pancada. \$ Copia, quantidade. \$ Infortunio, desgraça" (e outras que estão sublinhadas acima).

Vale ressaltar que, embora as definições se repitam, elas acarretam deslizamentos de sentido, pois há movimentos parafrásticos e polissêmicos.

GOLPE. Pancada. IEtus, us. Mafc.CIc. Plaga, \&. Fem. Virgil. Vid. Pancada. Algumas vezes se usa de percussus, us. Malsc. \& de Percussio, onis. Fem. Desta opiniaõ nacem os differentes modos de se mostrar anojado, como são os golpes, que se dão nos peitos, nas pernas, na cabeça. (BLUTEAU ,1712-1728)

GOLPE, s.m. pancada, ou ferida de corpo impelido, ou atirado. (MORAES SILVA, 1789)

Isso significa dizer que enquanto no dicionário de Moraes Silva algumas definições repetem-se, como por exemplo: "GOLPE, pancada"; parafraseando e retomando os espaços do dizer de Bluteau, o autor (re)formula esses dizeres e apresenta deslizamentos e acréscimos/apagamentos de sentidos. Orlandi (2001, p. 36) explica que, ao fazer uma paráfrase, provocamos deslizamentos de sentido, pois a simples repetição e a (re)formulação do mesmo dizer apresenta deslocamentos de sentidos que apontam para o âmbito da polissemia. Nessa perspectiva, a definição do verbete é construída no movimento entre a paráfrase e a polissemia, uma vez que essas noções estão inter-relacionadas e atuam nos processos de significação.

A partir do século XIX, a lexicografia brasileira apresenta um movimento importante na elaboração de dicionários. É preciso lembrar que houve acréscimos dos "vocabulários de brasileirismos" nos monolíngues português e, ao mesmo tempo, acontece a gramatização das línguas indígenas e do português do Brasil, conforme assevera Nunes (1996). Assim, o dicionário de Moraes Silva, publicado em 1813, evoca sentidos e memórias produzidas em determinadas condições de produção. Vejamos, abaixo, a definição de golpe no dicionário do século XIX, no Quadro 3.

Quadro 3: Verbete golpe século XIX

\section{SÉCULO XIX}

Dicionário da Língua Portuguesa de Antonio de Moraes Silva (1813)

GOLPE, s.m. Pancada, ou ferida de corpo impelido, ou atirado. \$. Copia, quantidade: v. g. um bom golpe de pedraria. Amaral, 7. hum bom golpe de dinheiro, de vinho, de agua. M. Conq. $\$$ - de cavalaria, ou infantaria, de gente. B. i. Ajuntou hum golpe dos seus. Castan. 3. f. 218. Vir de golpe; muitos, e de sobresalto. Ined. 2. 307. \$. "Os batéis tornavão por outro golpe de gente" B. i. 8. 5. \$. De golpe: de repente, rapidamente. "os dias minguão de golpe”. B. 3. 5. Infortunio, desgraça: v. g. por morte. $\$$ Talho, que se fazia por ornato nos vestidos antigos; tinhão por baixo vivos, ou estofos de còr diversa do da peça. $\S$. De golpe, adv. a um tempo, de repente. V. do Arceb. i. 5. De um golpe; de huma vez: v. g. pòr de hum golpe gente no muro inimigo assaltado. Castan L. 3. f. 214. \$. Golpe de mestre: rasgo, lance, acção de homem, que sabe bem daquilo a que se refere o golpe.

Fonte: Elaboração nossa a partir dos dicionários 
No dicionário de Moraes Silva (1813), vemos que há reformas e acréscimos na definição do verbete golpe, em comparação ao publicado em 1789. O autor acrescenta:

Vir de golpe; muitos, e de sobresalto. Ined. 2.307. \$. “Os batéis tornavão por outro golpe de gente” B. i. 8. 5.

$\S$. De golpe: de repente, rapidamente. "os dias minguão de golpe”.

Notemos que houve uma ampliação de sentido na definição de golpe, ao colocar: "Vir de golpe; muitos, e de sobresalto. $\$$. De golpe: de repente, rapidamente", acrescentando a ideia de ações imprevistas e, ainda, exibe exemplos apresentando explicitações de uso sobre o sentido, a saber: "Os batéis tornavão por outro golpe de gente” B. i. 8. e $\$$. "os dias minguão de golpe”.

Desse modo, compreendemos que o processo de significação é marcado por movimentos de acréscimos, deslizes de sentidos, exemplificações de situações de uso e, também, por estabilizações que constroem o imaginário do verbete golpe.

Vejamos, abaixo, as definições ${ }^{5}$ de golpe nos dicionários do século XX, no Quadro 4.

Quadro 4: Verbete golpe século XX

SÉCULO XX

\begin{tabular}{|c|c|c|c|}
\hline $\begin{array}{c}\text { Grande e Novíssimo Dicionário da } \\
\text { Língua Portuguesa } \\
\text { Laudelino Freire } \\
1939-1944\end{array}$ & $\begin{array}{l}\text { Grande Dicionário da Língua } \\
\text { Portuguesa } \\
\text { Antonio de Moraes Silva } 1945\end{array}$ & $\begin{array}{l}\text { Novo Dicionário Brasileiro } \\
\text { Melhoramentos Ilustrado } \\
\text { Adalberto Prado e Silva } 1962\end{array}$ & $\begin{array}{c}\text { Novo Dicionário da Língua Portuguesa } \\
\text { Aurélio Buarque de Holanda Ferreira } \\
1975\end{array}$ \\
\hline $\begin{array}{l}\text { GOLPE, s.m. B. lat. colpus. Pancada com } \\
\text { instrumento cortante ou contundente. } \\
\text { 2. Ferimento, fenda, ferida ou brecha } \\
\text { feita com instrumento cortante ou } \\
\text { contundente. } \| \text { 3. Acontecimento } \\
\text { funesto inesperado; infortúnio, } \\
\text { desgraça. } \| \text { 4. Crise } \| \text { 7. Disposição } \\
\text { decisiva que se toma em qualquer } \\
\text { negócio. } \\
\text { s.m. Ato violento a que um governo } \\
\text { recorre para sustentar o poder ou } \\
\text { evitar alguma tentaiva contra o estado. } \\
\text { || 2. Trama pela qual um ou mais } \\
\text { indivíduos por meios violentos } \\
\text { derribam o governo estabelecido para } \\
\text { construir um novo. }\end{array}$ & $\begin{array}{l}\text { GOLPE. s.m. (do b. lat. colpu-). Pancada } \\
\text { com objeto desfechado ou caído: <um } \\
\text { golpe de espada>; \| Fig. Sucesso infeliz, } \\
\text { dor moral, infortúnio, lances, crimes, } \\
\text { revés: <a morte do pai foi um golpe } \\
\text { terrível>; Fig. Ataque criminoso e cruel; } \\
\text { ironia, sarcasmo, insolto: <Sabereis } \\
\text { entender onde se há de dar o golpe, ter de } \\
\text { vossa mão sapateiro de arte, buscar } \\
\text { propósitos pera pregoardes que andais } \\
\text { custoso...>, Jorge Ferreira Vasconcelos, } \\
\text { Eufrosina I, 1.||De golpe, de repente, } \\
\text { subitamente. \|Obs. É preciso cuidado } \\
\text { com o emprego desta palavra, que dá } \\
\text { origem a muitos galicismos. Assim: evita- } \\
\text { se golpe de vento, dizendo rajada ou } \\
\text { lufada; golpe de Sol, dizendo raçada (de } \\
\text { Sol) ou insolação; golpe de mestre, } \\
\text { dizendo lanço de mão de mestre; golpe de } \\
\text { teatro dizendo lance ou relancearde olhos, } \\
\text { relance, vista de olhos; etc. }\end{array}$ & $\begin{array}{l}\text { Golpe, s.m. (gr. Kolaphos, pelo l. v.). } 1 . \\
\text { Ferimento ou pancada com } \\
\text { instrumento cortante ou contundente. } \\
\text { 2. Corte, incisão. } 3 . \text { Desgraça, } \\
\text { infortúnio. 4. Ímpeto, chôfre. 5. Crise. } \\
\text { 10. Gír. Manobra traiçoeira. } \\
\text { G. de estado, Dir.: medida } \\
\text { extraordinária pela qual o chefe do } \\
\text { governo de um país altera ou tenta } \\
\text { alterar, violentamente, as suas } \\
\text { instituições políticas, para tornar-se } \\
\text { ditador, quase sempre com o apoio das } \\
\text { forças armadas. G. de mão, Gal.: } \\
\text { tentativa ousada e rapidamente } \\
\text { executada; expedição, ataque } \\
\text { imprevisto. Fig. Ataque criminoso e } \\
\text { cruel; ironia, sarcasmo, insolto: } \\
<\text { Sabereis entender onde se há de dar o } \\
\text { golpe, ter de vossa mão sapateiro de arte, } \\
\text { buscar propósitos pera pregoardes que } \\
\text { andais custoso...>, Jorge Ferreira } \\
\text { Vasconcelos, Eufrosina I, } 1 .\end{array}$ & $\begin{array}{l}\text { Golpe. [Do gr. Kólaphos, 'bofetada', pelo lat. } \\
\text { colophu.] S.m. 1. Movimento pelo qual um } \\
\text { corpo se choca se com outro; pancada: Deu } \\
\text { violentos golpes na mesa. 4. Ato ou gesto pelo } \\
\text { qual alguém alcança ou tenta alcançar } \\
\text { outrem com um objeto, uma arma branca } \\
\text { etc.: Deu-lhe um golpe com o chicote; Levou } \\
\text { um golpe de sabre; Recebeu um golpe mortal } \\
\text { com o facão. 5. Ação súbita e inesperada: } \\
\text { golpe de audácia. 6. Acontecimento súbito e } \\
\text { inesperado: golpe de sorte. 10. Ímpeto, } \\
\text { impulsivo. Golpe de Estado. Subversão da } \\
\text { ordem constitucional. De golpe. De repente; } \\
\text { de súbito, de chofre; repentinamente, } \\
\text { subitamente: "ergueu-se de golpe, deu duas } \\
\text { voltas e atirou-se à cama chorando..." } \\
\text { (Machado de Assis, Quincas Borba, p. 73). }\end{array}$ \\
\hline
\end{tabular}

Fonte: Elaboração nossa a partir dos dicionários

\footnotetext{
${ }^{5}$ Estas definições de golpe nos dicionários do século XX foram elaborações nossas, a partir dos dicionários: (1) Grande Dicionário da Língua Portuguesa, de Antonio de Moraes Silva, de 1945; (2) Grande e Novíssimo Dicionário da Língua Portuguesa, de Laudelino Freire, de 1939-1944; (3) Novo Dicionário Brasileiro Melhoramentos Ilustrado, de Adalberto Prado e Silva, de 1962, e (4) Novo Dicionário da Língua Portuguesa, de Aurélio Buarque de Holanda Ferreira de 1975.
} 
De modo geral, o que podemos observar é que a marcação léxico-sintática é a mesma (s.m.), porém apresenta variações no que diz respeito à origem etimológica: latim e grego.

Além disso, vemos exemplos de situações de uso aliados ao sentido apresentado:

GOLPE. Ataque criminoso e cruel; ironia, sarcasmo, insolto:

- $\quad<$ foram golpes cruéis os do sarcasmo de Camilo $>$; $<$ Sabereis entender onde se há de dar o golpe, ter de vossa mão sapateiro de arte, buscar propósitos pera pregoardes que andais custoso...>, Jorge Ferreira Vasconcelos, Eufrosina I, 1, 16.

(MORAES SILVA, 1945).

GOLPE. Ato ou gesto pelo qual alguém alcança ou tenta alcançar outrem com um objeto, uma arma branca etc.:

Definição

4 Exemplo

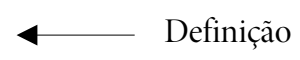

- Deu-lhe um golpe com o chicote; Levou um golpe de sabre; Recebeu um golpe mortal com o facão.

(FERREIRA, 1975).

As exemplificações estão presentes apenas nos dicionários de Moraes Silva (1945), e no de Aurélio Buarque de Holanda Ferreira (1975). É necessário observar que, no dicionário de Moraes Silva (1945), os exemplos são retirados de obras literárias portuguesas, evocando uma filiação ainda de Portugal e há citações explícitas das referências: "Eufrosina, Jorge Ferreira Vasconcelos”; já no dicionário de Ferreira (1975), os exemplos parecem expor situações de uso que funcionam como representativas de uma linguagem praticada no Brasil, corroborando a afirmação de Nunes (2008).

No que se refere aos sentidos, vemos que são atos que remetem aos aspectos físicos, a saber: "Ato ou gesto pelo qual alguém alcança ou tenta alcançar outrem com um objeto". Também relacionam-se à ações desleais, exemplo: "Ataque criminoso e cruel e Manobra traiçoeira”. Assim, na tensão dos complexos movimentos de deslizes, repetições, exemplificações e atualizações de sentido vai-se produzindo uma materialidade discursiva que atravessa ideologicamente os processos de significação do verbete golpe.

Ao mencionar a tensão dos complexos movimentos no processo de significação do verbete golpe, é importante destacar o dicionário de Laudelino Freire, intitulado de O Grande e Novíssimo Dicionário da Língua Portuguesa, que foi publicado em 1939-1944, pela editora A Noite. Esse dicionário acrescenta à definição de golpe um sentido que marca seu processo de significação, como também evoca historicamente uma memória do Brasil. Vejamos:

GOLPE DE ESTADO, s.m. Ato violento a que um governo recorre para sustentar o poder ou evitar alguma tentativa contra o estado. || 2. Trama pela qual um ou mais indivíduos por meios violentos derribam o governo estabelecido para construir um novo.

Esse acréscimo pode ser explicado devido ao período de sua publicação (1939-1944). Nesta época, o Brasil caracterizou-se pelo regime político denominado por Estado Novo (1937-1945), dirigido por Getúlio Vargas. Esse período ficou marcado pelo fato de que em 1937 estavam previstas eleições presidenciais, mas, em decorrência da denúncia de Vargas sobre a existência de um plano comunista (Plano Cohen), as eleições não aconteceram. Então, aproveitando-se da existência desse plano, da instabilidade política 
que o Brasil passava e com o apoio dos militares, Vargas determinou o fechamento do Congresso Nacional e impôs uma nova constituição, realizando um golpe de Estado e instituindo o Estado Novo.

Desse modo, compreendemos que a introdução do sentido: golpe de Estado está ligado às condições de produção do dicionário e à memória histórica e política do Brasil nessa época. Assim, além de ampliar a definição de golpe, o dicionário de Laudelino Freire produz saberes que vão implicar nas redes de significação das memórias lexicográfica e histórica.

É relevante lembrar que a partir da introdução de golpe de Estado realizada por Laudelino Freire, os dicionários de Adalberto Prado e Silva (1962) e de Aurélio Buarque de Holanda Ferreira (1975) também incluíram ao verbete golpe, a definição de golpe de estado em seus dicionários. Contudo, com outras definições, vejamos:

G. de Estado, Dir.: medida extraordinária pela qual o chefe do governo de um país altera ou tenta alterar, violentamente, as suas instituições políticas, para tornar-se ditador, quase sempre com o apoio das forças armadas (PRADO E SILVA, 1962).

Golpe de Estado. Subversão da ordem constitucional (FERREIRA, 1975).

Desse modo, o verbete golpe, sobretudo do ponto de vista de uma lexicografia discursiva, estabiliza os sentidos que não devem ser esquecidos, no que se refere à materialidade discursiva, a saber: pancada com instrumento, a trama por meios violentos, a manobra traiçoeira, desonesta, a subversão da ordem constitucional do Estado, o ataque imprevisto - e remete às diferenças e contradições dos acontecimentos na sociedade.

É com essas significações, portanto, que vai se constituindo o imaginário do verbete golpe. Não de maneira direta nem linear com as coisas do mundo; pelo contrário, os sentidos surgem no movimento da história e na tensão entre o político e o ideológico.

\section{CONSIDERAÇÕES FINAIS}

Com este estudo, compreendemos que o dicionário apresenta a ideia de uma língua imaginária que, por sua vez, remete às condições de produções e à memória. Além disso, vimos que esse imaginário, ao estabilizar sentidos do verbete golpe, não deixa a língua estável. Pelo contrário, deparamo-nos com uma língua imaginária atravessada por movimentos de resistência, de retomadas de acontecimentos políticos e históricos do Brasil e de contradições que evocam discursos outros que a constituem em sua materialidade.

O verbete golpe, no processo de significação, apresentou: (1) indicação da categoria gramatical (s.m.), exceto no de Bluteau (17121728), que não faz essa marcação; (2) exemplificações de situações de uso do verbete golpe nos dicionários: Vocabulario Portuguez e Latino (1712-1728), de Bluteau, Dicionário da Língua Portuguesa, de Antonio de Moraes Silva (1813), Grande Dicionário da Língua Portuguesa, de Antonio de Moraes Silva (1945), Novo Dicionário da Língua Portuguesa, de Aurélio Buarque de Holanda Ferreira (1975); (3) repetições de palavras e de situações de uso; (4) acréscimos e apagamentos de sentidos; (5) paráfrases, reformulando dizeres de outros dicionários; e (6) deslizamentos de sentidos.

É preciso ressaltar que a paráfrase, os apagamentos e os deslizamentos de sentido situam e marcam ideologicamente pontos de tensão e de movimento nos dicionários, uma vez que, na perspectiva teórico-analítica da AD e da HIL, as noções de paráfrase e polissemia estão articuladas. Desse modo, a definição do verbete golpe parece estar se repetindo e dizendo a mesma coisa, mas, ao analisarmos recorrendo aos confrontos e movimentos que afetam o político, o ideológico e a historicidade dos sentidos, vemos que a significação está em transformação, atravessada por discursos outros. 
Faz-se necessário salientar também que a reflexão, ora apresentada, está longe de esgotar o tema proposto devido à complexidade e à multiplicidade de dicionários que envolvem o verbete golpe nos séculos XVIII, XIX e XX, por isso fizemos o recorte discursivo explicitado na metodologia.

Ressalte-se, ainda, o indicativo de que mais estudos devem ser realizados para discutir e analisar o imaginário do verbete golpe na história lexicográfica. Todavia, esperamos que nossas reflexões, ainda que em caráter preliminar, possam trazer explicitações dos processos de significação do verbete golpe nos dicionários analisados.

\section{REFERÊNCIAS}

AUROUX, S. A revolução tecnológica da gramatização. Campinas: Ed. da Unicamp, 1992.

A hiperlíngua e a externalidade da referência. In: ORLANDI, E. (Org.). Gestos de leitura. Da História no Discurso. Campinas: Unicamp, 1997. p. 245-255.

BLUTEAU, R. Vocabulario portuguez e latino. Lisboa: Colégio das Artes da Companhia de Jesus, 1712-1728.

FERREIRA, A. B de H. Novo dicionário da língua portuguesa. Rio de Janeiro: Nova Fronteira, 1975.

FREIRE, L. Grande e novíssimo dicionário da língua portuguesa. Rio de Janeiro: A Noite, 1944.

NUNES, J. H. Dicionários no Brasil: análise e história. Campinas: Pontes, 2006.

. Discurso e instrumentos linguísticos no Brasil: dos relatos de viajantes aos primeiros dicionários. 1996. 269 f. Tese (Doutorado em Linguística) - Programa de Pós-graduação do Instituto de Estudos da Linguagem, UNICAMP, Campinas, 1996.

. A construção dos leitores nos discursos dos viajantes e missionários. Dissertação (Mestrado em Linguística) - Programa de Pós-graduação do Instituto de Estudos da Linguagem. UNICAMP, Campinas, 1992.

. Dicionarização no Brasil: condições e processos. In: PETTER, M. (Org.). História do saber lexical e constituição de um léxico brasileiro. São Paulo: Humanitas/Campinas: Pontes, 2002. p.99-119.

. Uma articulação da análise de discurso com a história das ideias linguísticas. Letras, Santa Maria, v. 18, n. 2, p. 107-124, 2008a.

. Dicionário, sociedade e língua nacional: o surgimento dos dicionários monolíngües no Brasil. In: LIMA, I. S; CARMO, L. do (Org.). História social da língua nacional. Rio de Janeiro: Edições Casa de Rui Barbosa, 2008b. p. 353-374.

ORLANDI, E. P. Terra à vista - discurso do confronto: Velho e Novo Mundo. Campinas: Ed. da Unicamp; São Paulo: Cortez, 1990. . Discurso, imaginário social e conhecimento. Revista Em Aberto, Brasília, ano 14, n. 61, p. 52-59. jan./mar. 1994.

. Interpretação: autoria, leitura e efeitos do trabalho simbólico. 4.ed. Campinas: Pontes, 2004.

(Org.). História das ideias linguísticas: construção do saber metalingüístico e constituição da língua nacional. Campinas:

Pontes; Cáceres: Unemat, 2001. 
ORLANDI, E. P. Língua e conhecimento linguístico. São Paulo: Cortez, 2002.

PÊCHEUX, M. Semântica e discurso: uma crítica à afirmação do óbvio. Trad. Eni Puccinelli Orlandi. Campinas, SP: Editora da UNICAMP, 1988.

SILVA, A. P.e. Novo dicionário brasileiro Melhoramentos ilustrado. São Paulo: Melhoramentos, 1962.

SILVA, A. de M. Diccionario da lingua portuguesa. Lisboa: Typographia Lacerdina, 1813.

Diccionario da lingua portuguesa. composto pelo Padre D. Rafael Bluteau, reformado e acrescentado por Antonio de Moraes Silva, Lisboa, 1789.

Grande dicionário da língua portuguesa. 10. ed. Lisboa: Confluência, 1945.

SILVA, M. V. da. O dicionário e o processo de identificação do sujeito analfabeto. In: GUIMARÃES, E.; ORLANDI, E. P. (Org.). Língua e cidadania: o Português no Brasil. Campinas, SP: Pontes, 1996. 151-162.

TOLEDO, C. N. A democracia populista golpeada. In: TOLEDO, C. N. (Org.). 1964: visões críticas do golpe. 2. ed. Campinas, SP: Editora da Unicamp, 2014. p. 39-57.

Recebido em 26/04/2017. Aceito em 11/07/2017. 